\title{
Transport of Water in Plants
}

\author{
Ernst STEUDLE \\ Lehrstuhl Pflanzenökologie, University of Bayreuth, D-95440 Bayreuth, Germany
}

(Received January 28, 2002)

\begin{abstract}
A sufficient balance in the supply and loss of water is an important prerequisite for the occurrence, growth and productivity of plants. For a higher plant, the water balance is given by the difference between water uptake across the root and water losses by transpiration in the shoot. Much is known about the mechanisms used by plants to minimize water losses across stomata. For technical reasons, much less is known about the input side of the balance, i.e. about the regulation of water uptake from the soil. Results are summarized on water uptake in great detail (cell, tissue, organ, and whole plant levels). Experimental findings result in models of the water transport across roots which incorporate molecular mechanisms, i.e. the gating of water channels (aquaporins) by different external and internal factors. The recent criticism of the cohesion theory of the ascent of sap in plants is discussed. Recent results support the theory. They show that the evidence gainst the theory was based on artifacts. Overall, there is support that, to some extent, plants behave like "hydraulic machines" and that water flow within plants may be described by just a few physical principles.
\end{abstract}

Keywords : apoplast, aquaporins/water channels, cohesion/tension (CT) mechanism, composite transport model, osmosis, pressure probe

\section{INTRODUCTION}

By far, the amounts of water which are required for growth and development of higher plants are bigger than those of all other material such as mineral ions or carbon dioxide. In fact, plants waste large amounts of water which is often a limiting factor. Depending on conditions and plant type, the amounts of water passing plants per day are several times bigger than the mass of all leaves. Transpiration is an evil brought about by the fact that plants have to open stomata to allow for the assimilation of $\mathrm{CO}_{2}$ which diffuses into leaves along a concentration gradient which is much less steep than that for the diffusive loss of water vapour on the same path. The mechanisms which regulate the exchange of water vapor and $\mathrm{CO}_{2}$ tend to optimize water losses. They are well understood (Schulze, 1986 ; Jones, 1998). Much less understood are the mechanisms by which the supply of the plant with water and flows within the plant are regulated.

Water relations deal with the movement of water in the plant-soil-air-continuum (SPAC). Plant water status is the result of the difference between input from the root and output caused by transpiration. To some extent, plants are "hydraulic machines." Water flow through individual plants, stands or ecosystems is largely passive. It is not driven by metabolic energy and follows simple force/flow relations. Regulations or controls are imposed at different

Corresponding author: Ernst Steudle, fax : +49-921-55-2564, e-mail : ernst.steudle @ uni-bayreuth.de 
critical points by adjusting flow resistances. To set these resistances may require metabolic energy such as during the regulation of stomatal width. Often stomatal resistance is the biggest in the system and limiting. However, other resistances may be variable as well such as the hydraulic resistance during water uptake or the axial hydraulic resistance which governs long distance transport in the vesssels of xylem. Different from stomata, much less is known about the parameters that govern these latter resistances within the liquid phase. The topic is much discussed at present for two reasons. First, the discussion relates to the regulation of water flow at the cell level. Here, transport proteins play a dominating role. In the early 90 s, aquaporins or water channels have been discovered which have been shown to contribute to most (up to 95\%) of the water permeability of plasma membranes (Preston et al., 1992; Chrispeels and Maurel, 1994 ; Steudle and Henzler, 1995 ; Maurel, 1997 ; Schäffner, 1998 ; Kjellbom et al., 1999; Tyerman et al., 1999). The second reason is that there has been a vivid discussion about the physical nature of the axial flow of water in the xylem which is usually described in terms of the cohesion/tension (CT) theory (Böhm, 1893; Kramer and Boyer, 1995 ; Tyree, 1997; Steudle, 2001). The validity of this mechanism has been questioned (Balling and Zimmermann, 1990 ; Zimmermann et al., 1993, 1994, 2000). In the following, the state of the discussion is briefly summarized taking into account the three levels, i.e. the cell level (aquaporins or water channels), the tissue/organ level (root) and the long distance transport (CT mechanism).

\section{LEVEL OF CELLS (MEMBRANES) : WATER CHANNELS}

It is known for about 50 that cell membranes contain pores which facilitate water transport (e.g. Dainty, 1963 ; House, 1974 ; Stein, 1986). In animal and plant cells, pores have been identified as aquaporins or water channels (Fig. 1). Aquaporins belong to an ancient family of channel proteins with a molecular weight of about $30 \mathrm{kDa}$ (Preston et al., 1992; Chrispeels and Maurel, 1994; Maurel, 1997; Schäffner, 1998). To date, more than 30 putative water channels have been identified which are thought to be rather selective for water just because of their small internal diameter. Different from ion channels, much less is known about the molecular physiology of water channels. This is due to the fact the transport of water cannot be measured with the same sensitivity as that of ions. In intact cells, the cell pressure probe may used which has been developed some time ago in the author's lab (Fig. 2; e.g. Steudle, 1993).

As ion channels, water channels exist in an open or closed state. There is not much known about gating mechanisms. Several external and internal factor affect the open/closed state of water channels. External factors which tend to close channels are stresses such as high salinity or concentration, heavy metals, drought, or low temperature (Azaizeh et al., 1992 ; Steudle and Henzler, 1995; Kjellbom et al., 1999; Tyerman et al., 1999; Steudle, 2001). Anoxia and oxdidative stresses affect the open/closed state as well (Birner and Steudle, 1993; Henzler and Steudle, 2000, unpublished). Heavy metals (e.g. $\mathrm{Hg}^{2+}$ ) act by an attachment to $\mathrm{SH}$ groups (cystein) of the protein which results in a conformational change and channel closure. For the other factors, mechanisms are less clear. Since the temperature dependence of water permeability (hydraulic conductivity, $L_{\mathrm{p}}$; osmotic water permeability, $P_{\mathrm{f}}$ ) of cell membranes has been often found to be similar to that of the viscosity or self diffusion coefficient of bulk water, it has been assumed that water passing channels experiences a surrounding which is similar to that in bulk water (hydrogen bonding within the protein ; Fig. 1). There is evidence that, at least in the narrow part of channels, water passes in single files (no-pass pores). Although rather selective for water, channels have been shown to allow some slippage of small organic solutes (Hertel and Steudle, 1997; Kjellbom et al., 1999; 

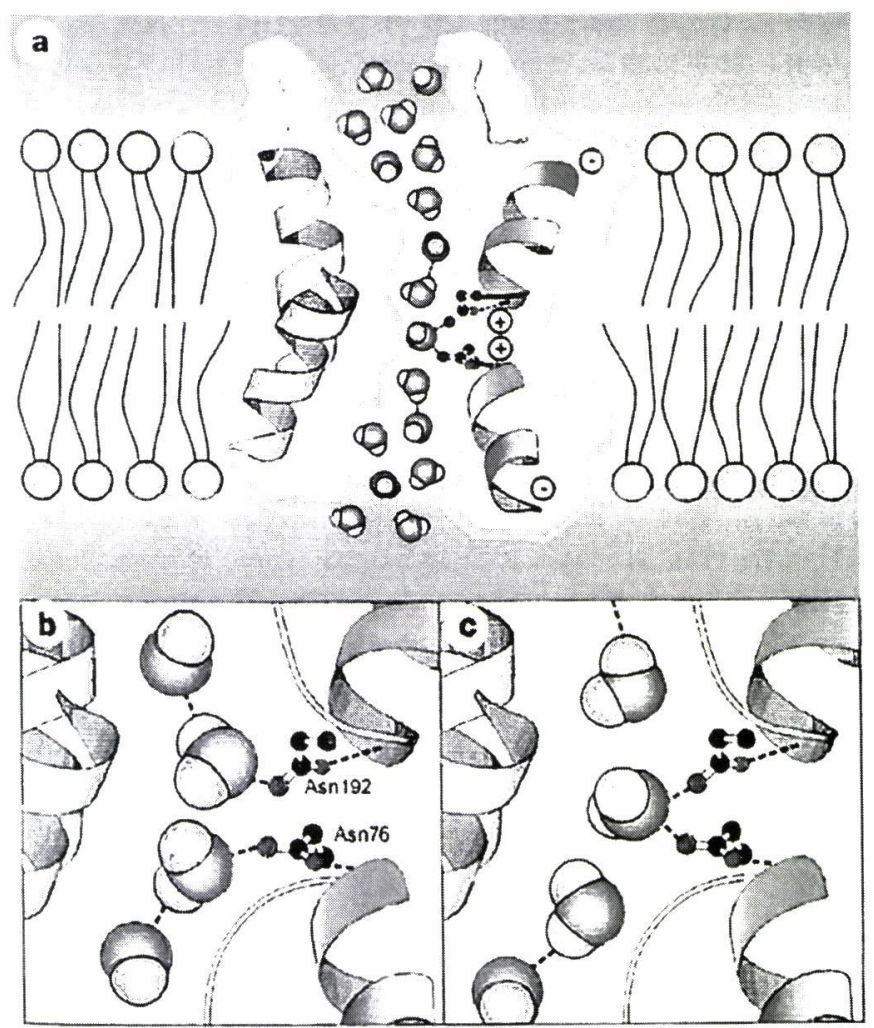

Fig. 1 Sketchy representation of the permeation of water across an aquaporin (water channel).

Within the channel water moves in a single file (a) forming hydrogen bonds with polar groups of the protein $(b, c)$. Adapted from Murata et al. (2000).

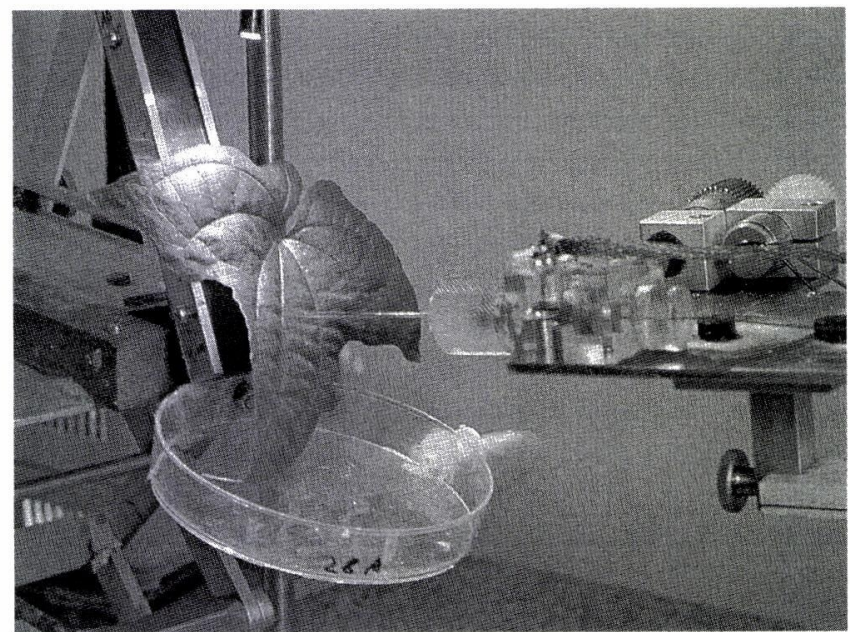

Fig. 2 Cell pressure probe introduced into an individual leaf cell. For a detailed description of the technique, see Steudle (1993). 
Tyerman et al., 1999 ; Henzler and Steudle, 2000).

Besides the usual inhibition of water channels by mercurials (mostly $\mathrm{HgCl}_{2}$ is used) or high salinity, other inhibitors have been employed as well. It is known for a long time that nutrient deprivation reduces the hydraulic conductance of roots (e.g. deprivation of nitrogen and phosphorus; Radin and Eidenbock, 1984 ; Radin and Matthews, 1989). The reduction is caused by a decrease of water channel density in the membrane (Carvajal et al., 1996). When wheat plants are grown under conditions of $\mathrm{N}$ or $\mathrm{P}$ deprivation, they lose their sensitivity against $\mathrm{HgCl}_{2}$ treatment, i.e. water channels are not expressed or activated under these conditions. Obviously, there are links between water and nutrient relations. It has been speculated that nutrient shortage causes a cascade of events which results in an inhibition of aquaporins (Clarkson et al., 2000). Another important finding is that water channel activity may have a diurnal rhythm. In roots of Lotus japonicus, there was a diurnal rhythm in water uptake which was anticipated by a diurnal rhythm in the amount mRNA which encodes for water channels (Henzler et al., 1999).

When water channels are closed, there are interesting responses in the overall osmotic behavior of cells. When using rapidly permeating solutes which cross the membrane largely via the bilayer (different low molecular weight organic solutes such as monohydric alcohols, acetone, amides and the like), osmotic treatment of Chara internodes resulted in negative or anomalous osmosis (Steudle and Henzler, 1995 ; Henzler and Steudle, unpublished). This is theoretically predicted when treating the cell membrane as a composite transport system (Steudle and Henzler, 1995). When channels were closed, the permeability of solutes was bigger than that of water. To date, the most obvious response of this type has been found for Chara internodes, when water channels were reversibly closed in the presence hydroxyl radicals (Henzler and Steudle, unpublished). Besides the decrease in water permeability (hydraulic conductivity), the striking phenomenon of negative osmosis in the presence of channel closure is the most obvious demonstration of the fact that water channels represent the main passage for water across cell membranes.

\section{THE STRESS HORMON ABSCISIC ACID AFFECTS WATER CHANNEL ACTIVITY}

The stress hormone abscisic acid (ABA) is produced in roots under conditions of water shortage. It is exported to the shoot as a signal which induces closure of stomata. Effects of $\mathrm{ABA}$ on root water uptake has been somewhat contradictory in the literature. Recent measurements with corn roots demonstrated that ABA increases the water permeability of roots and that it induces big increase in root cell $L_{\mathrm{p}}$ which, however, were transient. More detailed long term investigations (again with corn roots) have shown that there are mechanical effects on cell $L_{\mathrm{p}}$ involved which interact with the ABA effect (mechanical stresses; Wan and Steudle, unpublished). Sufficiently big changes in turgor as during water shortage in the soil, result in a channel closure by some kind of a mechanical stimulus. This, however, could be reversed in the presence of $\mathrm{ABA}$. The effect was different from that of membrane stretching (stretch-induced closure of ion channels in animal cells). Rather than being caused by the action of pressure itself, it appeared that the intense water flow across channels was the cause which was induced by pressure changes. For ABA, the results have also shown that there is a by-pass flow in the apoplast which contributes to the root-to-shoot signal of the hormone (Freundl et al., 1998, 2000 ; Hose et al., 2000, 2001 ; Steudle, 2000a, b).

\section{TISSUE AND ORGAN LEVEL : WATER UPTAKE BY PLANT ROOTS}

Changes in the activity of water channels affect the permeability at the next levels of 
organization, i.e. at the tissue and organ level. However, at these levels an apoplastic component of water flow around protoplasts has to be considered as well. The latter may be even dominating. In roots, the contribution of apoplastic water flow is reduced by the existence of apoplastic barriers in the exo- and endodermis (Casparian bands, suberin lamellae ; Zimmermann and Steudle, 1998 ; Zimmermann et al., 2000). This fact makes it difficult to just relate a variability in tissue/organ water relations to changes in water channel activity. The relative importance of the two pathways (cell-to-cell and apoplastic) vary much in response to growing conditions such as water shortage, high salinity, nutrient deprivation, anoxia and other stresses, which affect the formation of apoplastic barriers as well as water channel activity (Steudle and Peterson, 1998). This results in the flexible capacity of roots to take up water which is known for a long time (see references in Steudle and Peterson, 1998). Data obtained in the author's lab in the past decade at both the cell and root level have shown that the flexibility may be best interpreted in terms of a 'composite transport model' with parallel pathways for water (transcellular, symplastic, and apoplastic flow components). The model explains the fact that hydrostatic tensions in the xylem during demands for water from the shoot increase the root hydraulic conductivity which is low at its absence. The model also explains low reflection coefficients of roots. A flexibility due to changes in root cell hydraulics may be incorporated as well. External parameters such as stresses may affect both the cell-to-cell and the apoplastic path. According to the composite transport model, roots tend to optimize their water and solute (nutrient) relations in that apoplastic barriers effectively interrupt a back flow of nutrients once taken up actively. However, barriers are not completely impermeable for water. The apoplastic passage may be used for water as well, when necessary to improve the capacity for water uptake. On top of this, there is the possibility to adjust water channel activity in some kind of an 'active' regulation, when water channels are activated by phosphorylation (Johansson et al., 1996). Hence, there is a 'metabolic' gating of channels besides of effects which are governed by physicochemical parameters.

The combination of the root and cell level (i.e. the combination of the root and cell pressure probe techniques) provides a tool to work out the contributions of water flow along different pathways and hence to verify the model. The results collected so far indicate that, depending on requirements, roots are able to switch between pathways. On one hand, root water flow is optimized in a way which allows sufficient uptake water at a high water permeability. On the other hand, however, roots provide a sufficient barrier for an efflux of nutrients. For example, roots of hygrophytes such as rice tend to have rather strong apoplastic barriers which results in a small flexibility in the root hydraulic conductivity as compared with other herbs. As a consequence, the regulation of water flow across the root is limited. Hence, rice plants may suffer from water shortage in the shoot even in paddy fields (Miyamoto et al., 2001).

\section{THE COHESION/TENSION MECHANISM AND THE LONG DISTANCE FLOW OF WATER IN PLANTS}

The 100 year old cohesion-tension theory of botanist postulates that transpiration causes a tension in xylem sap which is transmitted down to roots to act as the driving force for water uptake from the soil. There are many indirect observations in favour of the CT theory, the most important being the indirect measurement of xylem tensions with the aid of the Scholander bomb (for a review and literature, see Steudle, 2001). The difficulty with the CT theory is that it postulates high tensions or negative pressures in the xylem, i.e. pressures which are much smaller than vacuum. Since water under tension is in a metastable state, the theory has been occasionally questioned such as recently by Zimmermann and co-workers (Balling and 
Zimmermann, 1990 ; Zimmermann et al., 1993, 1994, 2000). For the first time, these authors used the cell pressure probe to directly measure xylem pressure (tensions). They found that tensions were much smaller than postulated according to the CT theory. Tensions were substantially smaller than those obtained with the Scholander bomb and did not respond to transpiration. Hence, the CT theory was rejected and the validity of measurements with the Scholander bomb questioned. As a consequence, some workers in the field quickly proposed alternative mechanisms of xylem water flow, some of them being not really in agreement with basic physics (Canny, 1998). Eventually, it turned out that the basis of Zimmermann's measurements was not correct. He overlooked the limitation of the pressure probe for measuring high tensions (Steudle, 1995). This was recently shown in Bayreuth in cooperation with Prof. Tyree and his student Chungfang Wei (Wei et al., 1999a, b, 2000). The data indicated that the pressure probe may be only used to measure tensions of up to $1 \mathrm{MPa}$ (10 bar). At higher tensions (more negative pressures), there were problems with the cavitation of the probe itself, which were not checked for in Zimmermann's lab. In the range of tensions measured so far in Bayreuth, there was a good agreement between the Scholander bomb and the pressure probe. Tensions depended on the rate of transpiration as proposed by the CT theory. As a result, the discussion on CT mechanisms is now focusing on the ability of plants to maintain high tensions in the xylem for longer periods of time and to provide mechanisms for refilling of cavitated vessels (Canny, 1998; Tyree et al., 1999; Cochard et al., 2000; Zwienicki and Holbrook, 2000 ; Steudle, 2001).

In conclusion, there are recent important developments in the field of plant water relations which contribute to the question as to how plants are able to effectively regulate their water status at different levels in order to save water:

(1) At the level of individual cells/membranes, the high mobility of water is related to the existence of special transport molecules in the membrane (aquaporins or water channels). The structure of channels is largely known. Much less is known about the molecular physiology of channels (gating functions). The activity of transporters is effectively regulated by different parameters such as water potential, drought, salinity, high concentration, nutrient status, mechanical triggers, stress hormones (ABA), heavy metals, anoxia, and oxidative stress. Although the mechanisms of the different gating functions have not yet been worked out, this, nevertheless, provides a molecular basis of plant water relations.

(2) Plants are "hydraulic machines." They regulate their water status by a adjusting several key resistances within the SPAC. Besides the stomata, the hydraulic resistance of roots plays an important role in controling shoot water status. At the root level, both a physical model and the adjustment of water channel activity interact to optimize water uptake according to the needs of the shoot. Quantitative evaluation of transport at different passages across roots have shown that the contribution of pathways may vary. There may be purely physical or metabolically controlled processes (apoplastic vs. cellular water flow : composite transport model of root). It is not yet clear how, at the root level, water channel activity is gated by various external and internal parameters.

(3) Besides the water channel activity, the apoplastic component of water flow is important at the tissue and organ level. In roots, detailed research at the cell and organ level has shown how the switching between pathways may be performed. According to the composite transport model, the coarse regulation of root $L_{\mathrm{p}}$ is physical in nature. A fine regulation is provided by water channel activity. The model optimizes water and solute (nutrient) relations in that roots exhibit a sufficient permeabilty to water which is regulated or adapted according to the needs of the shoot.

(4) At the whole-plant level, the cohesion/tension mechanism dominates the transport in xylem vessels. The recent criticism of this key mechanism was based on artifacts. 
However, there are still difficulties with the CT mechanism. The stability of states of tensions lacks a sufficient explanation. Convincing mechanisms of the refilling of cavitated vessels have not yet been presented.

(5) Different from regulation at the level of stomata, the regulation of water flows within the liquid phase appears to be much more complicated and complex. However, the importance of regulation in this area is as important as that of gas exchange, because water status is the difference between input and output functions. Because of technical difficulties to measure input functions with sufficient accuracy, much less is known about the regulation of water input.

\section{REFERENCES}

Azaizeh, H., Gunse, B., Steudle, E. 1992. Effects of $\mathrm{NaCl}$ and $\mathrm{CaCl}_{2}$ on water transport across root cells of maize (Zea mays L.) seedlings. Plant Physiol. 99 : 886-894.

Balling, A., Zimmermann, U. 1990. Comparative measurements of the xylem pressure of Nicotiana plants by means of the pressure bomb and pressure probe. Planta 182 : 325-338.

Birner, T., Steudle, E. 1993. Effects of anaerobic conditions on water and solute relations and active transport in roots of maize (Zea mays L.). Planta 190 : 474-483.

Böhm, J. 1893. Capillarität und Saftsteigen. Ber. Dtsch. Bot. Ges. 11 : 203-212.

Canny, M. J. 1998. Transporting water in plants. Am. Sci. 86 : 152-159.

Carvajal, M., Cooke, D. T., Clarkson, D. T. 1996. Responses of wheat plants to nutrition deprivation may involve the regulation of water-channel function. Planta 199: 372-381.

Chrispeels, M. J., Maurel, C. 1994. Aquaporins: the molecular basis of facilitated water movement through living plant cells. Plant Physiol. $105: 9-15$.

Clarkson, D. T., Carvajal, M., Henzler, T., Waterhouse, R. N., Smyth, A. J., Cooke, D. T., Steudle, E. 2000. Root hydraulic conductance: diurnal aquaporin expression and the effects of nutrient stress. J. Exp. Bot. 51 : 61-70.

Cochard, H., Bodet, C., Ameglio, T., Cruiziat, P. 2000. Cryo-scanning electron microscopy observations of vessel content during transpiration in walnut petioles. Facts or artifacts? Plant Physiol. 124 : 1191-1202.

Dainty, J. 1963. Water relations of plant cells. Adv. Bot. Res. 1 : 279-326.

Freundl, E., Steudle, E., Hartung, W. 1998. Water uptake by roots of maize and sunflower affects the radial transport of abscisic acid and the ABA concentration in the xylem. Planta 207: 8-19.

Freundl, E., Steudle, E., Hartung, W. 2000. Apoplastic transport of abscisic acid through roots of maize : Effect of the exodermis. Planta 210 : 222-231.

Henzler, T., Waterhouse, R. N., Smyth, A. J., Carvajal, M., Cooke, D. T., Schäffner, A. R., Steudle, E., Clarkson, D. T. 1999. Diurnal variations in hydraulic conductivity and root pressure can be correlated with the expression of putative aquaporins in the root of Lotus japonicus. Planta 210 : 5060.

Henzler, T., Steudle, E. 2000. Transport and metabolic degradation of hydrogen peroxide in Chara corallina : model calculations and measurements with the pressure probe suggest a transport of $\mathrm{H}_{2} \mathrm{O}_{2}$ across water channels. J. Exp. Bot. 51 : 2053-2066.

Hertel, A., Steudle, E. 1997. The function of water channels in Chara: the temperature dependence of water and solute flows provides evidence for composite membrane transport and for a slippage of small organic solutes across water channels. Planta 202 : 324-335.

Hose, E., Steudle, E., Hartung, W. 2000. Abscisic acid and the hydraulic conductivity of roots : a celland root-pressure probe study. Planta 211 : 847-882.

Hose, E., Clarkson, D. T., Steudle, E., Schreiber, L., Hartung, W. 2001. The exodermis-a variable apoplastic barrier. J. Exp. Bot. 52 : 2245-2264.

House, C. R. 1974. Water Transport in Cells and Tissues. Edward Arnold, London.

Johansson, I., Larsson, C., Ek, B., Kjellbom, P. 1996. The major integral proteins of spinach leaf plasma 
membranes are putative aquaporins and are phoshorylated in response to $\mathrm{Ca}^{2+}$ and apoplastic water potential. Plant Cell 8 : 1181-1191.

Jones, H. G. 1998. Stomatal control of photosynthesis and transpiration. J. Exp. Bot. 49 : 387-398.

Kjellbom, P., Larsson, C., Johansson, I., Karlsson, M., Johanson, U. 1999. Aquaporins and water homeostasis in plants. Trends Plant Sci. 4 : 308-314.

Kramer, P. J., Boyer, J. S. 1995. Water Relations of Plants and Soils. Academic Press, Orlando.

Maurel, C. 1997. Aquaporins and water permeability of plant membranes. Annu. Rev. Plant Physiol. Plant Mol. Biol. 48 : 399-429.

Miyamoto, N., Steudle, E., Hirasawa, T., Lafitte, R. 2001. Hydraulic conductivity of rice roots. J. Exp. Bot. 52 : 1835-1846.

Murata, K., Mitsuoka, K., Hirai, T., Walz, T., Agre, P., Heymann, J. B., Engel, A., Fujiyoshi, Y. 2000. Structural determinants of water permeation through aquaporin-1. Nature 407: 599-605.

Preston, G. M., Carroll, T. P., Guggino, W. B., Agre, P. 1992. Appearance of water channels in Xenopus oocytes expressing red cell CHIP28 protein. Science $256: 385-387$.

Radin, J. W., Eidenbock, M. P. 1984. Hydraulic conductance as a factor limiting leaf expansion of phosphorous-deficient cotton plants. Plant Physiol. 75 : 372-377.

Radin, J. W., Matthews, M. A. 1989. Water transport properties of cells in the root cortex of nitrogenand phsophorous-deficient cotton seedlings. Plant Physiol. 89 : 264-268.

Schäffner, A. R. 1998. Aquaporin function, structure, and expression : there are still surprises to come up in water relations. Planta $204: 131-139$.

Schulze, E.-D. 1986. Carbon dioxide and water vapor exchange in response to drought in the atmosphere and soil. Annu. Rev. Plant Physiol. 37 : 247-274.

Stein, W. D. 1986. Transport and Diffusion Across Cell Membranes. Academic Press, Orlando.

Steudle, E. 1993. Pressure probe techniques: basic principles and application to studies of water and solute relations at the cell, tissue, and organ level. In "Water Deficits : Plant Responses from Cell to Community" (ed. by Smith, J. A. C., Griffith, H.). BIOS Scientific Publishers, Oxford, p 5-36.

Steudle, E. 1995. Trees under tension. Nature 378: 663-664.

Steudle, E. 2000a. Water uptake by roots : effects of water deficit. J. Exp. Bot. 51 : 1531-1542.

Steudle, E. 2000b. Water uptake by plant roots: an integration of views. Plant Soil 226: 45-56.

Steudle, E. 2001. The cohesion-tension mechanism and the acquisition of water by plant roots. Annu. Rev. Plant Physiol. Plant Mol. Biol. 52 : 847-875.

Steudle, E., Henzler, T. 1995. Water channels in plants : do basic concepts of water transport change? J. Exp. Bot. 46 : 1067-1076.

Steudle, E., Peterson, C. A. 1998. How does water get through roots? J. Exp. Bot. 49: 775-788.

Tyerman, S. D., Bohnert, H. J., Maurel, C., Steudle, E., Smith, J. A. C. 1999. Plant aquaporins: their molecular biology, biophysics and significance for plant water relations. J. Exp. Bot. 50 : 1055-1071.

Tyree, M. T. 1997. The cohesion-tension theory of sap ascent. current controversies. J. Exp. Bot. 48 : 1753-1765.

Tyree, M. T., Salleo, S., Nardini, A., Assunta Lo Gullo, M., Mosca, R. 1999. Refilling of embolized vessels in young stem of laurel. Do we need a new paradigm? Plant Physiol. 120 : 11-22.

Wei, C., Steudle, E., Tyree, M. T. 1999a. Water ascent in plants : do ongoing controversies have a sound basis? Trends Plant Sci. $4:$ 372-375.

Wei, C., Tyree, M. T., Steudle, E. 1999b. Direct measurement of xylem pressure in leaves of intact maize plants. A test of the cohesion-tension theory taking hydraulic architecture into consideration. Plant Physiol. 121 : 1191-1205.

Wei, C., Steudle, E., Tyree, M. T. 2000. Reply: Water ascent in plants. Trends Plant Sci. 5 : $146-147$.

Zimmermann, H. M., Steudle, E. 1998. Apoplastic transport across young maize roots: effects of the exodermis. Planta 206 : 7-19.

Zimmermann, H. M., Hartmann, K., Schreiber, L., Steudle, E. 2000. Chemical composition of apoplastic transport barriers in relation to radial hydraulic conductivity of corn roots (Zea mays L.). Planta 210 : 302-311.

Zimmermann, U., Benkert, R., Schneider, J., Rygol, J., Zhu, J. J., Zimmermann, G. 1993. Xylem pressure and transport in higher plants and tall trees. In "Water Deficits : Plant responses from cell to Community” (ed. by Smith, J. A. C., Griffiths, H.). BIOS Science Publishers, Oxford, p 87-108. 
Zimmermann, U., Meinzer, F. C., Benkert, R., Zhu, J. J., Schneider, H., Goldstein, G., Kuchenbrod, E., Haase, A. 1994. Xylem water transport: is the available evidence consistent with the cohesiontension theory? Plant, Cell Environ. 17 : 1169-1181.

Zimmermann, U., Wagner, H. J., Schneider, H., Rokitta, M., Haase, A., Bentrup, F. W. 2000. Water ascent in plants : the ongoing debate. Trends Plant Sci. 5 : 145-146.

Zwienicki, M. A., Holbrook, N. M. 2000. Bordered pit structure and vessel wall surface properties. Implications for embolism and repair. Plant Physiol. 123 : 1015-1020. 